https://helda.helsinki.fi

\title{
Generations and Political Engagement
}

\section{Nemcok, Miroslav}

Oxford University Press

2021

Nemcok , M \& Wass , H 2021, Generations and Political Engagement . in W R Thompson

(ed.) , Oxford Research Encyclopedia of Politics . Oxford University Press , Oxford . https://doi.org/10.1093/acrefore/

http://hdl.handle.net/10138/328593

https://doi.org/10.1093/acrefore/9780190228637.013.1756

submittedVersion

Downloaded from Helda, University of Helsinki institutional repository.

This is an electronic reprint of the original article.

This reprint may differ from the original in pagination and typographic detail.

Please cite the original version. 


\title{
Generations and Political Engagement
}

\author{
Miroslav Nemčok \\ Hanna Wass
}

Published as:

Nemčok, M., and Wass, H. (2021) “Generations and Political Engagement”, In: Oxford Research Encyclopaedia of Politics.

\section{Summary}

The concept of generation constitutes a useful tool in order to understand the world of politics. Trends in political behavior typical for the youngest generation are not only indicative for the future development, but large differences between generations also reveal potential for intergenerational conflict and shift in the entire political paradigm. There are four important topics which need to be addressed in order to properly understand the body of research studying specifics of political behavior across generations and the use of generation as an analytical tool: (1) conceptual definition of generation, (2) its distinction from other time-related concepts, (3) methodological challenges in applying the time-related factors in research, and (4) understanding the wider implications of these factors for individuals' political behavior which have been already identified in the scholarship.

A political generation is formed among cohorts which experience the same event(s) during their formative years and become permanently influenced by them. Therefore, members of the 
same generation share similar socialization experiences which create a sense of group belonging and shape the attitudes and behavior throughout their lives. This definition of political generation is distinctive among the three time-related factors - age, period, and cohort - each of which have a well-grounded and distinctive theoretical underpinning.

However, a truly insightful examination of the time-related development in political engagement needs to utilize hybrid models that interacts age and period, or cohort and period. This imposes a challenge known as identification problem - age (years since birth), period (year), and cohort (year of birth) are perfect linear functions of each other and therefore conventional statistical techniques cannot disentangle their effects. Despite extraordinary effort and outstanding ideas, this issue has not been resolved yet in a fully reliable and hence satisfactory manner.

Regardless of methodological issues and attempts to solve them, the literature is already able to provide important findings resulting from cohort analysis of political engagement. This scholarship includes two major streams: First one focuses on voter turnout, exploring whether non-voting among the youngest generation is a main reason for the turnout decline in contemporary democracies. A second stream examines the generational differences in political engagement and concludes that low electoral participation among the youngest generation may be explained by young people being more engaged with non-institutionalized forms of political participation (e.g. occupations, petitions, protests, online activism).

Keywords: Generations; Age-period-cohort Analysis; Age Effect; Generational Effect; Period Effect; Political Engagement; Voter Turnout; Identification Problem; Generational Replacement 


\section{Understanding and Approach to Politics across Generations}

A generational approach to politics has been emphasized in several areas during the past few years. For example, in their study of democratic deconsolidation, Foa and Mounck (2016) suggested that "the millennial generation", born in 1980s, is less committed to the core principles of liberal democracy than previous generations. Brexit (re)opened a question of intergenerational justice (see Tozer, 2019): should the decision-making procedures be primary concerned with the wellbeing of the future generations instead of concentrating on maximising the short-term benefits? The same issue applies to fight against the climate change in which younger generations have taken an active role.

Each of these three cases reveal essential aspects of generation which make it such a useful concept in understanding the world of politics. First, the behavior of young generations is often perceived as indicative for future development. If current youth is considerably dissimilar than their predecessors, societal change will gradually occur through generational replacement (see Dalton, 2017, p. 84; Glenn, 2005, p. 2). Second, if the political preferences among various generations clearly differ from each other, it makes it difficult to formulate an intergenerational contract to consolidate the contradicting views; there is potential for political conflict. Finally, people experience the same events differently at different age. Those events experienced at formative years, namely late adolescence and early adulthood, can mobilize political action that shape the character of a particular generation for the rest of its life, as well as triggering a political shift in entire political paradigm.

However, there are some challenges and difficulties in using generation as an analytical tool. Several potential fallacies could occur due to confusion between the three time-related effects (age, cohort and period). Also, the unique character of generation as a concept may be insufficiently recognized, making it merely as a synonym for a cohort. When the differences in 
political engagement between two different cohorts occur because they are at different phases of their life-cycles, this pattern will mitigate as the social roles of the younger cohort changes. Generational effect refers to enduring differences between the cohorts due to dissimilar socialization experiences during late adolescence and early adulthood (see Neundorf \& Niemi, 2014, p. 2). And finally, period effect concerns the situation in which all cohorts are affected in a similar fashion. For instance, events like economic recession may reduce political engagement among all cohorts, with outcome level depending on point of departure. Another challenge is methodological as empirical investigation of generational effect sets special requirements both in terms of data and analytical techniques.

The role of generation in political engagement is addressed here from four different perspectives. First, the concept of political generation is defined. Second, discussed is the association between generation and the other two time-related factors and stressed the importance of understanding the potential interactions between all thee. The existing solutions for the socalled identification problem, i.e. disentangling age, generational and period effects from each other, are introduced in the third section. The fourth section offers a short review of the previous findings in the field of generational differences in political engagement. Building on the reviewed research topics, the last part suggests some future paths for the analysis of generations and political engagement.

\section{What is Political Generation?}

To understand the concept of generation, one needs to differentiate it from the term cohort (or age group). Cohort simply refers to groups of people born in the same period of time, and who have thus experienced the same events at the same age. Generational theory is interested in the influence of events on a particular cohort. In his classical account of generations, Mannheim 
(1952) argued that various cohorts experience the same societal events differently depending on their life situation and level of development. Societal generations are formed among cohorts who not only experienced the same events during their formative years (usually between the ages of 17 and 25), but were permanently influenced by them. For instance, baby-boomers born after the World War II could have been permanently empowered by the student and anti-war movements in the 1960s. Also the formation of the sense of belonging to the same group, that is, "generational consciousness", is an important element in this process (see Edmunds \& Turner, 2002). As a consequence, the members of the same generation tend to exhibit similar attitudinal and behavioral patterns.

Defining political generations on the bases of shared experiences implies a tight association with societal development. The time span of a political generation was originally perceived to vary between 15 to 30 years, but the pace of social change has shortened the period between generations (Braungart \& Braungart, 1986, p. 218; see also Kertzer, 1983). Thinking of the rapid achievements in technology, it becomes obvious that the current youth is growing up in a considerably different environment compared to those born a decade ago. This observation has accelerated the "generation production", manifested itself in labels such as "Y-generation" or "the Millennials" (those born in 1980s and 1990s).

Such a contest over defining generations underline the fact that any attempt to classify political generations is to some extent a political act itself. It is also possible that some fractions of the expected generation does not share the same experiences and/or they might not have a unifying effect even among those who do (cf. Wass, 2008, p. 34). Having said that, most existing classifications of generations are based on relatively similar ideas of the events that have influenced political participation in the twentieth century (Persson, Wass, \& Oscarsson, 2013, p. 257). 


\section{How to Disentangle the Concepts of Age, Generational and Period Effects}

As has been discussed so far, the expectation for generational effects is built on three necessary preconditions: (1) the members of the same generation share similar socialization experiences which took place during their late adolescence and early adulthood, (2) because of that, there is certain sense of group belonging, that is, understanding of who "we" are as political actors, and (3) those common societal experiences shape the attitudes and behavior throughout the lives of the particular generation.

While the definition sounds relatively clear-cut, the problem is that it requires a long period of time to separate a genuine generational effect from "normal" differences between various cohorts. For example, the curvilinear relationship between age and political participation is one of the seminal findings in political science literature (for reviews, see Dassonneville, 2017; Smets \& van Ham, 2013; Wolfinger \& Rosenstone, 1980, p. 37). Participation first slowly increase among young adults, then stays relatively stable throughout middle age, and gradually declines among senior citizens. During early stages of adulthood, young people tend to pay more attention to finishing their education, successfully launching their careers, looking for a spouse and starting a family. This effectively decreases the relevance of politics among their priorities. Once these tasks are accomplished, people find themselves embedded in social networks, including religious and civic organizations and various types of community associations, which encourage specialized skills and resources to engage in politics (Verba, Schlozman, \& Brady, 1995; Putnam 2000). Then among seniors participation decreases as mobility and societal involvement decreases.

This age effect is demonstrated on the left-hand side panel in Figure 1. It suggests that younger cohorts tend to converge with the older ones as they age in a situation in which the behavior of the older cohort has already been stabilized (Jennings \& Niemi, 1981, p. 119). A 
generational effect means that the differences between older and younger cohorts remain even after the latter ages (the middle panel in Figure 1). To make things even more complicated, a third time-related component is the period effect. As demonstrated on the right-hand side panel in Figure 1, a period effect has a similar impact on each cohort. Major events, such as an economic depression or technological innovation may either increase or decrease in political engagement across all age groups (Jennings \& Niemi, 1981, p. 122).
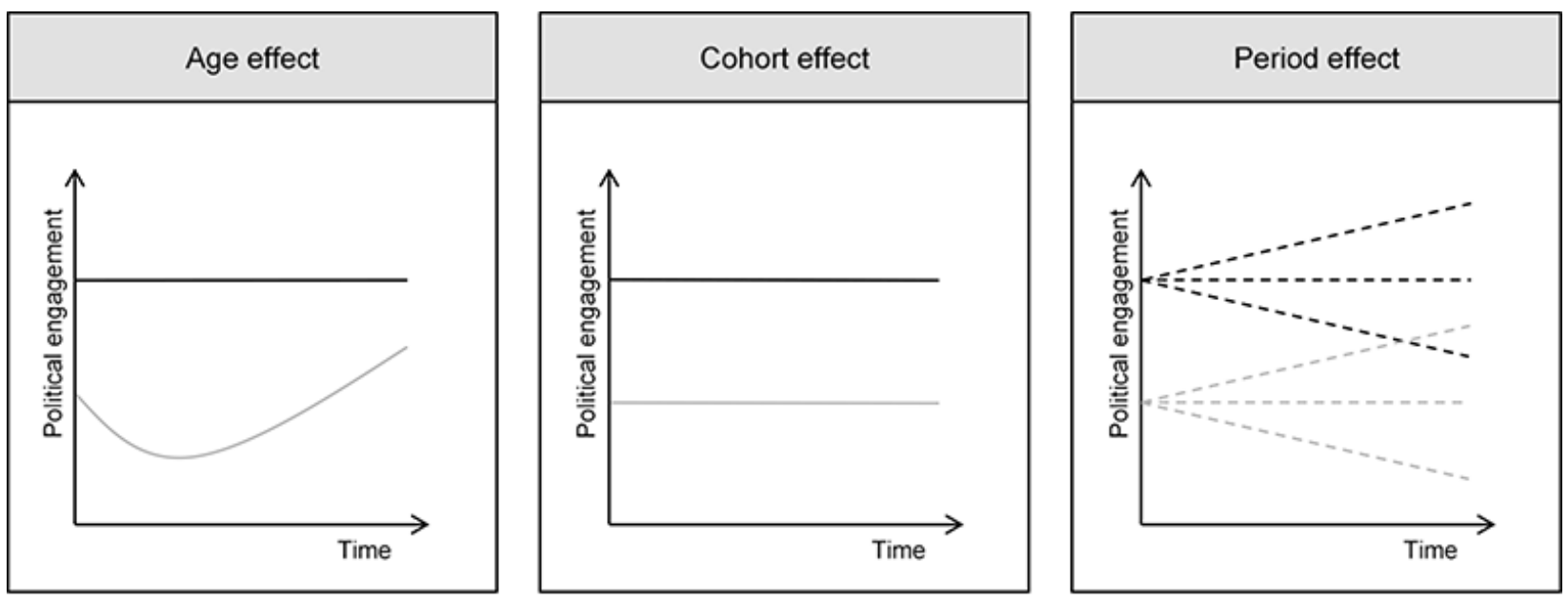

Older cohort Younger cohort

Figure 1: Demonstration of age, period and cohort effects. Source: Jennings and Niemi (1981, pp. 119-120) 
In reality, these three effects are not mutually exclusive. Instead, they may all take place simultaneously. This is possible to illustrate on the individual-level register data from four Finnish parliamentary elections (1987, 1999, 2015 and 2019). The 1987 (N=3,656,411) and 1999 $(\mathrm{N}=3,925,668)$ data, compiled by Statistics Finland, cover the entire mainland Finland, excluding Aland (an autonomous region of Finland). The two latter datasets, administrated by the Ministry of Justice, are based on the electoral wards that utilized electronic voting registers. In the parliamentary elections of 2015, electronic voting registers were used in 402 electoral wards in 115 municipalities. These wards include 24.2 percent of eligible voters residing in Finland $(\mathrm{N}=1,019,862)$. The corresponding figures for the 2019 elections are 658 electoral wards in 141 municipalities, which include 29.9 percent of the eligible voters $(\mathrm{N}=1,274,170)$.

Figure 2 is based on cross-sectional data from different time points. It shows that the young voted at lower level than their peers 32 years ago. ${ }^{1}$ For example, in 1987 people at the age of 30 voted at a 73 percent rate, but at a 85 percent rate among 50 -year-olds. Yet, it is impossible to say whether youth would follow the same path or even converge as the time goes by. To state it differently, there is an option for interaction between (a) age and period or (b) cohort and period (see Jennings \& Niemi, 1981, pp. 123, 212). In both cases cohorts begin apart, but whereas in the former the younger cohorts move much more rapidly, reflecting the life cycle effect, in the latter they then move in the same direction over time at an equal pace. 


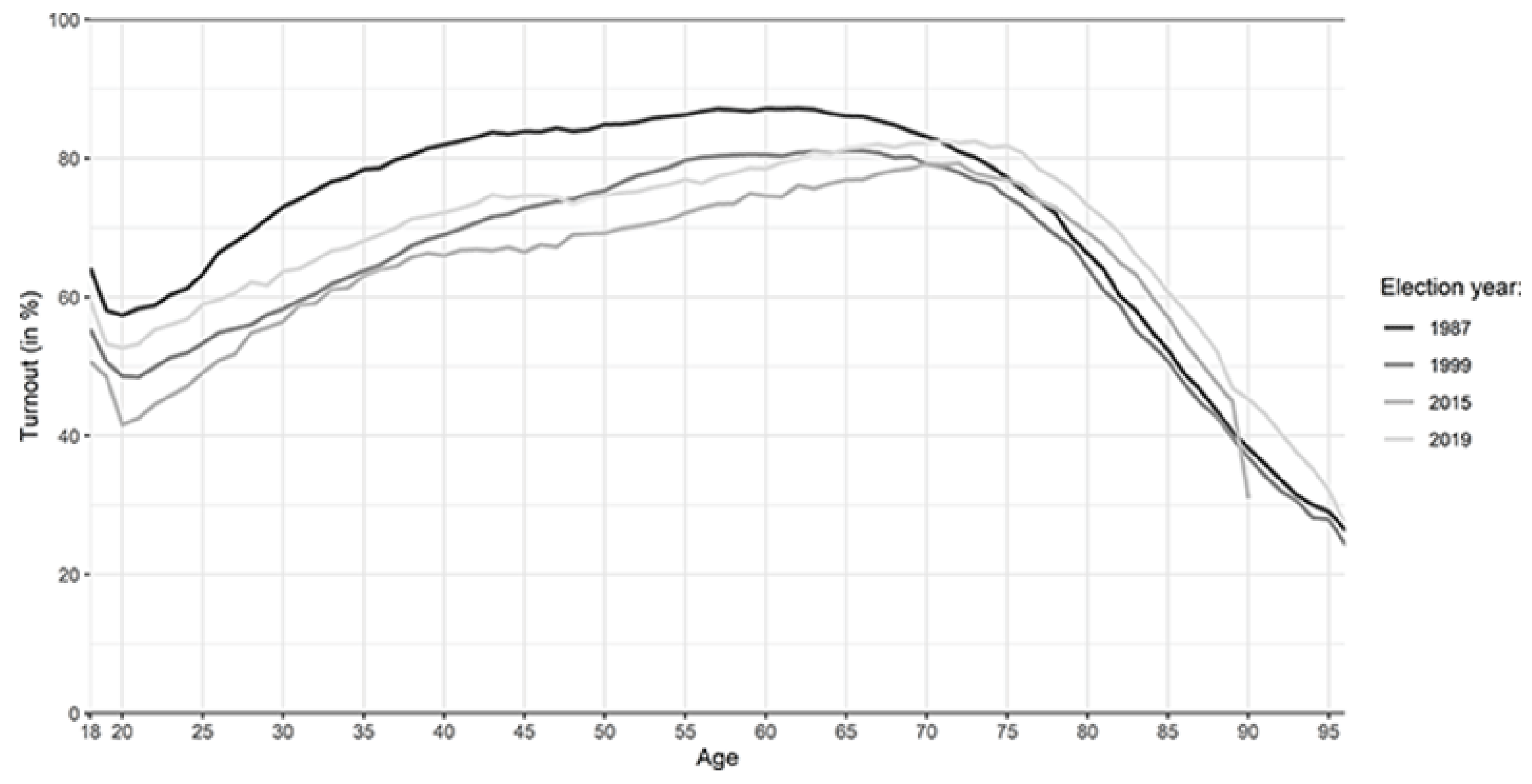

Figure 2: Turnout by age in the Finnish parliamentary elections of 1987, 1999, 2015 and 2019. 
To separate age and cohort effects, panel data that follows the same individuals from one election to another would be ideal (cf. Glenn, 2005, pp. 4-5). The collection of such data is burdensome and costly, thus panel studies are relatively rare. Usually cohort studies based on repeated cross-sectional data try to examine all three time-related effects simultaneously and disentangle them from each other. Different samples of each cohort are tracked across different points in time. Although the accuracy of such data is weaker compared to a genuine panel design, it does not suffer from panel conditioning effect, meaning that persons studied might be affected by their participation (cf. Glenn, 2005, pp. 4-5).

Table 1 is based on a mixture of both approaches. The table follow various Finnish cohorts from one election to another and shows their turnout in each of the four elections. For instance, those who were 18-year-olds in the parliamentary elections of 1987 were 30-year-olds in the elections of 1999, 46-year-olds in 2015 and 50-year-olds in 2019. This approach allows us to compare the turnout trajectories of age cohorts (in 1987) over the period of 32 years. ${ }^{2}$

What does Table 1 reveal? First, it is possible to see the same pattern reported in previous studies of voter turnout: among those who just vote after turning 18 is higher compared to the cohort a couple of years (see Bhatti, Hansen, \& Wass, 2016). From 1987 to 1999, turnout among those same cohorts, now 12 years older, increased only marginally (from $58.1 \%$ to $59.5 \%$ and from $57.4 \%$ to $60.4 \%$, consecutively). This finding originally made by Wass (2007, p. 650 ) suggest that there is a clear indication of a generational effect and only a weak age effect which impact becomes invisible during a long period. This interpretation seems to be proven correct since even in 2019 at the age of 51 and 52, turnout among these cohorts (75\% and 75.2\%) is nowhere near the figures among those who were at same age in 1987 (84.9\% and 85.2\%). Yet, it needs to be taken into account that the first 12 years of the electoral life cycle of those cohorts 
were accompanied by a substantial period effect in terms of turnout decline of 8.1 percentage points. It would have also been quite surprising if the youngest cohorts could have stayed immune to such overall development, namely that life cycle effect could have beaten the period effect. What seem to be happening is the interaction between period and generational effect.

Table 1: Turnout by cohort in the Finnish parliamentary elections of 1987, 1999, 2015 and 2019.

\begin{tabular}{|c|c|c|c|c|c|c|c|}
\hline \multicolumn{2}{|c|}{1987} & \multicolumn{2}{|c|}{1999} & \multicolumn{2}{|c|}{2015} & \multicolumn{2}{|c|}{2019} \\
\hline Age & $\begin{array}{c}\text { Turnout } \\
(\%)\end{array}$ & Age & $\begin{array}{c}\text { Turnout } \\
(\%)\end{array}$ & Age & $\begin{array}{c}\text { Turnout } \\
(\%)\end{array}$ & Age & $\begin{array}{c}\text { Turnout } \\
(\%)\end{array}$ \\
\hline & & & & & & 18 & 59.5 \\
\hline & & & & & & 19 & 53.2 \\
\hline & & & & & & 20 & 52.7 \\
\hline & & & & & & 21 & 53.2 \\
\hline & & & & 18 & 50.7 & 22 & 55.3 \\
\hline & & & & 19 & 48.5 & 23 & 56.0 \\
\hline & & & & 20 & 41.6 & 24 & 56.8 \\
\hline & & & & 21 & 42.6 & 25 & 59.0 \\
\hline & & & & 22 & 44.5 & 26 & 59.6 \\
\hline & & & & 23 & 45.8 & 27 & 60.6 \\
\hline & & & & 24 & 47.1 & 28 & 62.1 \\
\hline & & & & 25 & 49.1 & 29 & 61.7 \\
\hline & & & & 26 & 50.9 & 30 & 63.7 \\
\hline & & & & 27 & 51.8 & 31 & 64.1 \\
\hline & & & & 28 & 54.9 & 32 & 65.3 \\
\hline & & & & 29 & 55.6 & 33 & 66.7 \\
\hline & & & & 30 & 56.5 & 34 & 67.1 \\
\hline & & & & 31 & 58.9 & 35 & 68.1 \\
\hline & & & & 32 & 59.1 & 36 & 69.0 \\
\hline & & & & 33 & 61.1 & 37 & 70.0 \\
\hline & & 18 & 55.4 & 34 & 61.3 & 38 & 71.3 \\
\hline & & 19 & 50.7 & 35 & 63.1 & 39 & 71.7 \\
\hline & & 20 & 48.6 & 36 & 64.0 & 40 & 72.2 \\
\hline & & 21 & 48.5 & 37 & 64.4 & 41 & 72.8 \\
\hline & & 22 & 49.9 & 38 & 65.8 & 42 & 73.5 \\
\hline & & 23 & 51.3 & 39 & 66.3 & 43 & 74.7 \\
\hline & & 24 & 51.9 & 40 & 66.0 & 44 & 74.3 \\
\hline & & 25 & 53.3 & 41 & 66.8 & 45 & 74.6 \\
\hline & & 26 & 54.9 & 42 & 66.9 & 46 & 74.6 \\
\hline & & 27 & 55.5 & 43 & 66.7 & 47 & 74.4 \\
\hline & & 28 & 56.0 & 44 & 67.2 & 48 & 73.5 \\
\hline & & 29 & 57.5 & 45 & 66.5 & 49 & 74.3 \\
\hline 18 & 64.2 & 30 & 58.3 & 46 & 67.5 & 50 & 74.7 \\
\hline 19 & 58.1 & 31 & 59.5 & 47 & 67.2 & 51 & 75.0 \\
\hline 20 & 57.4 & 32 & 60.4 & 48 & 69.0 & 52 & 75.2 \\
\hline 21 & 58.3 & 33 & 61.8 & 49 & 69.1 & 53 & 75.8 \\
\hline 22 & 58.8 & 34 & 62.8 & 50 & 69.2 & 54 & 76.2 \\
\hline
\end{tabular}




\begin{tabular}{|c|c|c|c|c|c|c|c|}
\hline 23 & 60.3 & 35 & 63.8 & 51 & 69.9 & 55 & 76.9 \\
\hline 24 & 61.2 & 36 & 64.6 & 52 & 70.2 & 56 & 76.4 \\
\hline 25 & 63.3 & 37 & 65.9 & 53 & 70.7 & 57 & 77.4 \\
\hline 26 & 66.5 & 38 & 67.4 & 54 & 71.2 & 58 & 77.9 \\
\hline 27 & 67.9 & 39 & 68.3 & 55 & 72.1 & 59 & 78.6 \\
\hline 28 & 69.5 & 40 & 69.0 & 56 & 72.9 & 60 & 78.5 \\
\hline 29 & 71.3 & 41 & 69.8 & 57 & 73.4 & 61 & 79.4 \\
\hline 30 & 73.0 & 42 & 70.7 & 58 & 73.5 & 62 & 79.9 \\
\hline 31 & 74.1 & 43 & 71.6 & 59 & 74.9 & 63 & 80.8 \\
\hline 32 & 75.3 & 44 & 72.0 & 60 & 74.6 & 64 & 80.6 \\
\hline 33 & 76.6 & 45 & 72.8 & 61 & 74.5 & 65 & 81.4 \\
\hline 34 & 77.2 & 46 & 73.3 & 62 & 76.1 & 66 & 81.7 \\
\hline 35 & 78.4 & 47 & 73.8 & 63 & 75.7 & 67 & 82.0 \\
\hline 36 & 78.6 & 48 & 74.1 & 64 & 76.4 & 68 & 81.6 \\
\hline 37 & 79.8 & 49 & 74.9 & 65 & 76.9 & 69 & 82.1 \\
\hline 38 & 80.5 & 50 & 75.3 & 66 & 76.9 & 70 & 82.2 \\
\hline 39 & 81.4 & 51 & 76.5 & 67 & 77.8 & 71 & 82.5 \\
\hline 40 & 82.0 & 52 & 77.5 & 68 & 78.3 & 72 & 82.2 \\
\hline 41 & 82.5 & 53 & 78.1 & 69 & 78.6 & 73 & 82.4 \\
\hline 42 & 83.1 & 54 & 78.7 & 70 & 79.2 & 74 & 81.6 \\
\hline 43 & 83.8 & 55 & 79.7 & 71 & 79.1 & 75 & 81.8 \\
\hline 44 & 83.5 & 56 & 80.1 & 72 & 79.2 & 76 & 80.7 \\
\hline 45 & 83.9 & 57 & 80.3 & 73 & 77.8 & 77 & 78.4 \\
\hline 46 & 83.8 & 58 & 80.5 & 74 & 77.2 & 78 & 77.1 \\
\hline 47 & 84.4 & 59 & 80.6 & 75 & 76.9 & 79 & 75.5 \\
\hline 48 & 83.9 & 60 & 80.5 & 76 & 76.0 & 80 & 73.2 \\
\hline 49 & 84.1 & 61 & 80.3 & 77 & 73.8 & 81 & 71.4 \\
\hline 50 & 84.9 & 62 & 80.8 & 78 & 72.9 & 82 & 69.2 \\
\hline 51 & 84.9 & 63 & 81.0 & 79 & 71.0 & 83 & 66.1 \\
\hline 52 & 85.2 & 64 & 80.7 & 80 & 69.3 & 84 & 63.7 \\
\hline 53 & 85.8 & 65 & 81.1 & 81 & 67.5 & 85 & 60.7 \\
\hline 54 & 86.0 & 66 & 81.1 & 82 & 65.0 & 86 & 58.2 \\
\hline 55 & 86.3 & 67 & 80.8 & 83 & 63.3 & 87 & 55.4 \\
\hline 56 & 86.8 & 68 & 80.1 & 84 & 60.0 & 88 & 52.3 \\
\hline 57 & 87.1 & 69 & 80.2 & 85 & 57.1 & 89 & 46.9 \\
\hline 58 & 87.0 & 70 & 79.1 & 86 & 53.5 & 90 & 45.3 \\
\hline 59 & 86.8 & 71 & 78.8 & 87 & 50.6 & 91 & 43.2 \\
\hline 60 & 87.2 & 72 & 78.0 & 88 & 47.7 & 92 & 40.4 \\
\hline 61 & 87.1 & 73 & 76.8 & 89 & 45.0 & 93 & 37.6 \\
\hline 62 & 87.2 & 74 & 76.3 & 90 & 31.0 & 94 & 35.2 \\
\hline tal & 76.4 & & 68.3 & & 70.1 & & 72.1 \\
\hline
\end{tabular}

Note: The table follows the cohorts from election to election and shows their turnout in given elections. The overall turnout is based on official records among electorate residing in Finland (i.e. excluding emigrant voters).

Source: Statistic Finland. 
When moving towards the end of the $20^{\text {th }}$ century, a quite different story appears. Those who were 19 in the 1999 elections seem to be back on the life-cycle effect track. In the 2015 elections, their turnout was 63.1 percent, indicating an increase of 12.4 percentage points in 16 years. This was followed by an astonishing further boost to 71.7 percent in the 2019 elections. The life-cycle effect was most probably boosted by a positive period effect, manifested itself with gradually increasing overall turnout. The same applies to 19-year-olds in 2015 whose turnout was 7.5 percentage points higher in the 2019 elections. Consequently, it appears that the field has moved from generation-period to another hybrid model, namely to that of age-period effects.

Figure 3 illustrates both of hybrid models, namely an interaction between age and period and generation and period. In order to fully understand the time-related development in political engagement, it is necessary to investigate the interactions besides an attempt to detect "pure" age, generational and period effects. This is because the magnitude of the differences between generations is always affected by period (the right-hand side panel in Figure 2). In that respect, generational effect stands in the middle of age and period effects. However, in order to empirically study interactions, a strategy to model the main effects is needed. 

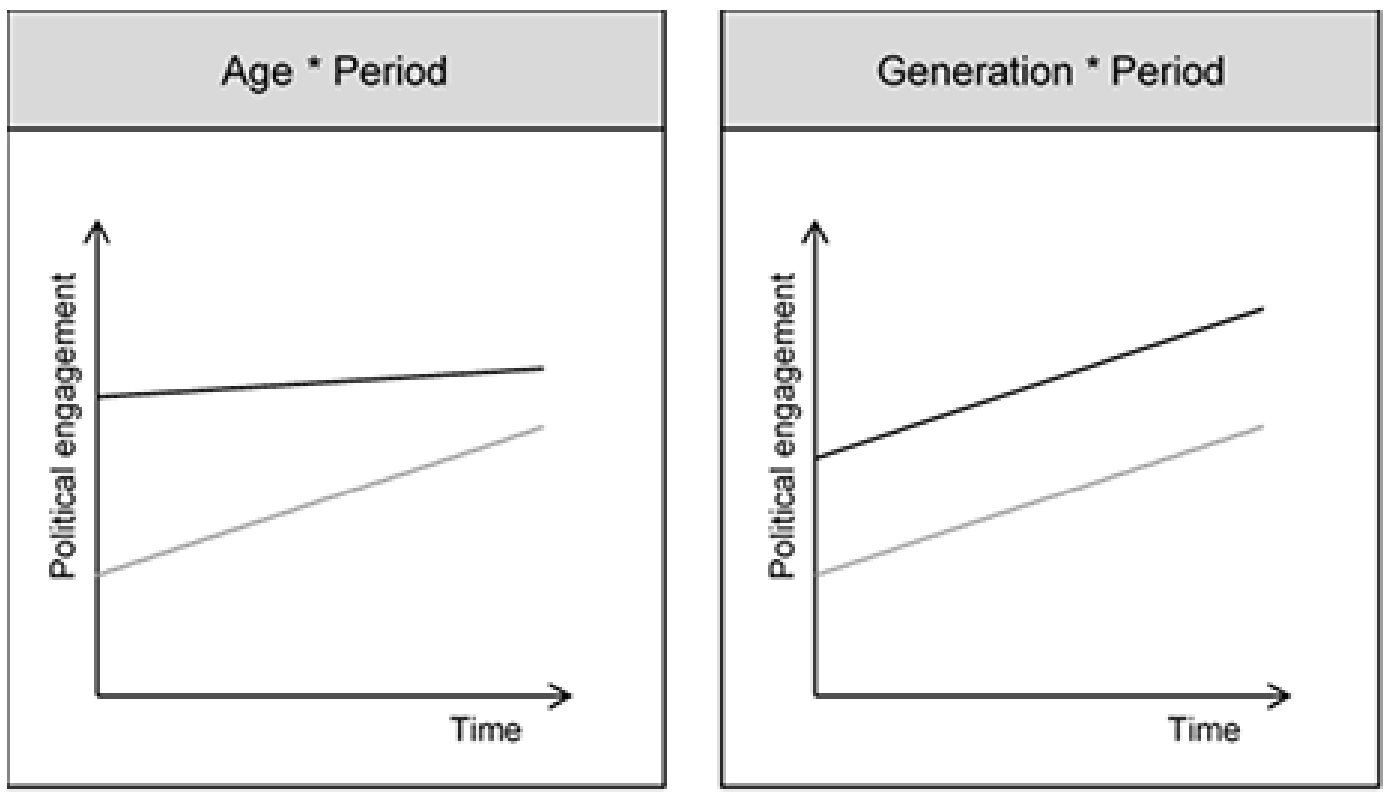

Older cohort

Younger cohort

Figure 3: Interactions between age and period and generation and period. Source: Jennings and Niemi 1981, 123.

\section{Identification Problem and Potential Solutions}

As discussed in previous sections, age, cohort and period effects all have different and wellgrounded theoretical underpinnings. Nevertheless, an effort to identify each of these trends separately on the bases of empirical data imposes methodological challenges that remain to be solved. The main reason for this is that before exploring the data at hand, it does not make much sense to decide the categorization of generations but simply treat each birth cohort as a single unit. However, when doing that, one ends up with a well-documented identification problem because age (years since birth), period (year), and cohort (year of birth) are exact linear functions of each other: 


$$
\text { Age }=\text { Period }- \text { Cohort }
$$

As a result, a perfect collinearity among these factors makes it statistically impossible for conventional techniques to separate age, period, and cohort effects without additional substantive assumptions (Glenn, 2005, p. 6; Winship \& Harding, 2008). Therefore, estimating cohort effects "is hampered by the fact that cohort is fully confounded with age when cohorts are compared at any one point in time, and fully confounded with period when cohorts are compared at any one point in the life cycle" (Dinas \& Stoker, 2014, p. 39).

An insightful overview by Achen and Wang (2019, pp. 120-122) identified three different strategies that scholars have employed in their endeavor to bypass the problem with collinearity. The first approach solves the collinearity issue by expecting that one of the effects, i.e. age, period, or cohort, is not present or it is identical to another effect and therefore its value can be set to zero (Mason, Mason, Winsborough, \& Poole, 1973, p. 253). Such an adjustment breaks down the perfect collinearity among the three parameters and makes the model estimable. Resulting parameters are interpreted as if the effect set to zero was also estimated by the model. Indeed, fixing one of the effects to a certain value introduces a serious substantive assumption into the analysis. Therefore, such a step requires considerable substantive reasoning prior to data analysis (Bell \& Jones, 2013). Ideally, researchers applying this strategy should explore all possible alternatives and thoroughly justify their choice (Fienberg \& Mason, 1985, p. 85). However, the implementation of this approach revealed that the results can change quite significantly depending on which of the effects is set to zero (or grouped with another one). Hence, it imposes additional challenges for researchers to demonstrate robustness of their findings, because already tiny errors in measurements and small omitted factors may introduce large bias into the results (Glenn, 2005, pp. 11-17). 
The second attempt to solve identification problem - called Intrinsic Estimator (IE) focuses directly on its mathematical properties. When statistical model tries to estimate the effects of age, period, and cohort, perfect collinearity between these factors causes that the statistical computation runs into an infinity of (statistically) equally good choices for the factors' coefficients. Therefore, the model lacks a rule which would determine estimate with the "best" properties. The field of mathematics offers some options how to bypass this kind of issues and the IE employs the one called Moore-Penrose inverse (Rao, 1973, pp. 24-27). Mathematical properties of Moore-Penrose estimator go way beyond the introductory topics, however, what has to be mentioned is that the choice made by this method is not grounded in any social, biological, nor cultural theory (Fosse \& Winship, 2018). Even though the application of IE can make ageperiod-cohort models estimable, the tests revealed that some statistically irrelevant choices in model specification can lead IE to produce results which are substantively different in their interpretations (te Grotenhuis, Pelzer, Luo, \& Schmidt-Catran, 2016). Yet, these choices are essential and common for the analysis of time-related factors, such as number of age, period, or cohort groups (Luo, 2013) and transformation of these categories into dummy variables (Pelzer, te Grotenhuis, Eisinga, \& Schmidt-Catran, 2015). Given these finding, it is hardly surprising that the concerns regarding the validity of IE outcomes quickly overshadowed its ability to solve identification problem and, hence, its application was sidelined in the social science research.

The last strategy is the hierarchical age-period-cohort (HAPC) model. This approach is possible due to increasing availability of survey data suitable for the analysis of time-related factors, namely repeated cross-sectional survey such as Comparative Study of Electoral Systems, European Social Survey, European/World Values Survey. Every HAPC analysis utilizes the fact that a specific age of every individual (measured in years from birth) could be perceived as being nested in a specific cohort and period (i.e. survey year). This opens up an opportunity to study 
age, period, and cohort effects via hierarchical (i.e. multi-level) model which studies the age effect on the level of individuals, but, on (an) upper level(s), it also captures more general trends exposed by cohorts as well as trends typical for the periods when a survey was conducted (Yang \& Land, 2006, 2013, pp. 125-230). However, every hierarchical model is still a linear regression and therefore it includes an assumption that its variables are random, i.e. uncorrelated with each other. This may become a problem in case of two variables, i.e. (generational) cohort and period, which may (at least approximately) correlate if the dependent variable follows a continuous upward/downward trend during the whole period covered by data. If this is the case, HAPC estimates are likely to be biased and misleading (Bell \& Jones, 2018). Unfortunately, long-term continuous trends tend to be the case of many attitudinal variables such as political engagement or turnout (O’Brien, 2015, pp. 133-136). The main space for errors is that an HAPC model provides no indication how accurate the estimated parameters are. Therefore, credibility of any HAPC model is dependent on careful (and challenging) validation of the random effects assumption (Achen \& Wang, 2019, p. 122).

Despite significant theoretical and methodological development, the conclusions of every age-period-cohort analysis of political engagement still contain a certain degree of uncertainty. However, the field has moved from the "impossibility" to disentangle age, period, and cohort effects (Bell \& Jones, 2013; Glenn, 2005, pp. 4-6) to necessity to carefully validate random effects assumption (Achen \& Wang, 2019, p. 122; O’Brien, 2015, pp. 133-136). Therefore, the progress is apparent, even though a fully satisfactory solution has yet to be discovered.

\section{Findings from Previous Cohort Analyses of Political Engagement}

Despite methodological challenges, the substantive changes in voting behavior in contemporary democracies since 1960s (Dalton, McAllister, \& Wattenberg, 2000; van der Brug, 2010) 
provoked scholars to explore whether generational replacement could explain these worrying trends. The idea to inspect the differences across cohorts was apparent due to two reasons: First, the generational differences on the basis of cohort analyses in party identification and affiliation, political engagement and voting were well detected already several decades ago (e.g. Abramson, 1976, 1979;; Glenn \& Grimes, 1968; Klecka, 1971). Second, changes in voting behavior emerged quite gradually which resemble the process of generational replacement (Franklin, 2004; Hooghe, 2004; van der Brug, 2010; van der Brug \& Kritzinger, 2012).

The scholarship studying the political behavior and attitudes of generations can be divided into two main streams. One focuses on voter turnout as described in the Finnish examples presented in the section How to Disentangle the Concepts of Age, Generational and Period Effects. This research explores whether a tendency of non-voting among the youngest generation constitutes the main reason for the aggregate-level decline in turnout in contemporary democracies. During the past decade, several cross-sectional cohort analyses of electoral participation have been conducted in countries like Canada, Finland, Germany, Norway, Sweden, Taiwan and United States (Achen \& Wang, 2019; Blais, Gidengil, Nevitte, \& Nadeau, 2004; Franklin, 2004; Gallego, 2009; Konzelmann, Wagner, \& Rattinger, 2012; Lyons \& Alexander, 2000; Öhrvall, 2016; Persson et al., 2013; Wass, 2007) and in the context of EP elections (Bhatti \& Hansen, 2012b). While the time span covered by the data and the categorization of generations vary across studies, the results generally indicate substantial differences in voting propensity between the younger and the older cohorts.

For instance, Blais et al. (2004) report that turnout in the Canadian parliamentary elections of 1968-2000 was about 20 percentage points lower among the "post-baby-boomers" (born after 1970) than among the "pre-baby-boomers" (born before 1945) at the age of 30. Bhatti and Hansen (2012b, p. 267) discovered an effect of almost identical magnitude in their examination 
of turnout in 11 European Union (EU) Member States in EP elections from 1979 to 2009. During that period, turnout among the pre-war generations was about 20 percentage points higher on average than turnout among the generation born in the 1970s and the post-1970s generation. The data from Norwegian parliamentary elections show that the estimated voting probability among 20-year-olds was 14 or 20 percentage points lower in 2001 compared to the parliamentary elections of 1964, depending on the educational level (Gallego, 2009, p. 27). This is particularly noteworthy as Norway, like Sweden, is a high-turnout country. Sweden shows a parallel, although a clearly more moderate pattern (Gallego, 2009). The latter finding was replicated by Persson, Wass, and Oscarsson (2013) who found that the voting propensity among "the dotnets" (born in 1977 and onwards) was eight percentage points lower than among "pre-universal generation" (born before 1918).

The results from the United States, Finland and few countries of post-communist Europe (i.e. Czech Republic, Slovakia, Hungary, and Poland) demonstrate substantially smaller generational effects. During a period of stable and increasing turnout in Finnish parliamentary elections (1975-1983), the average difference between the generation born in 1940-1959 and the generation born in 1960-1969 was 11.2 percentage points from ages 18 to 23 . During the period of declining turnout (1987-2003), the average difference between those born in 1940-1959 and the youngest generation (born from 1970 onwards) was 10.3 percentage points from ages 26 to 33 (Wass, 2007, p. 657). Lyons and Alexander (2000) report an even smaller effect in the US presidential elections of 1952-1996. Linek and Petrúšek (2016) found no generational effects in post-communist countries with an exception of Poland where the youngest generation actually turns out more often than other segments of the population. Hence, generational replacement cannot be the reason behind the overall decline in voter turnout across all the established 
democracies. Still, scholars in this field tend to agree that when cohorts are compared, younger ones generally show the lowest turnout rates (Blais \& Rubenson, 2013; Dassonneville, 2017).

The second stream of literature examines the generational differences in political attitudes. It acknowledges that the young generation is less likely to go to the polls compared to their parents when they were the same age (Norris, 2011; Quintelier, 2007) and aims to respond to the question whether young people are turning into more disengaged citizens. The main puzzle here is that even though young generations have comparably low level of political knowledge and comparably limited trust towards elected representatives and political system (Massing, 2002; Quintelier, 2007), the decline in political engagement of contemporary young people is more rapid than was the case for young cohorts in previous decades (Blais \& Rubenson, 2013; Russell, Fieldhouse, Purdam, \& Kalra, 2002).

In response, the field tends to converge on the opinion that the latest generational replacement brought also new means of political participation which are exercised by the most recent young cohorts. Norris argued already in 2002 that the major difference in political participation between the younger and the older cohorts is that young people "reinvented political activism" and instead of electoral politics, they are more often engaged with non-institutionalized forms of political participation (Amnå \& Ekman, 2014; Bennett \& Segerberg, 2013; Klingemann \& Fuchs, 1998; Norris, 2003; Torney-Purta, 2009) which includes occupations, campaigning for petitions, protests, online activism or simply displaying badges or stickers stating their political opinion on everyday objects (Bennett \& Segerberg, 2013; Dalton, 2017; European Commission, 2007; Sloam, 2016). Therefore, it seems to be the means of political participations which have changed due to generational change. 


\section{Politics across Generations: Directions for Future Research}

In 2005 , Glenn (2005, p. 52) noted that "[t]he future of cohort analysis is bright, primarily because the readily available data appropriate for this kind of research continue to accumulate, and there are already huge bodies of data that could be exploited to attain a better understanding of aging and social and cultural change". He was also optimistic about the methodological advances to approve analysis even without a perfect statistical remedy for the identification problem. It is easy to agree with this prognosis with a hindsight. The analysis of generations and political engagement is a flourishing field both in terms of theory formation and empirical investigations with rich datasets and sophisticated modeling techniques.

As regards to future development, the field would advance thanks to the work conducted in the three main directions. First, cohort analysis would benefit from paying a closer attention to hybrid models, namely interactions between age and period on the one hand and generation and period on the other. When looking at the panel data covering several decades, like the age and turnout from the Finnish parliamentary elections, it becomes obvious that the three time-related effects take place at the same time. Hence, generational effect is confounded by period effect and that needs to be taken properly into account in statistical models in order to derive accurate estimations.

Second, as especially generational and period but also age effect is heavily contextdriven $^{3}$, it is important to exceed cohort analysis besides Western democracies. Wass and Blais (2017, p. 478) remark that many of the established models and patterns of behavior do not likely apply among citizens who are socialized in non-democratic regimes. From that perspective, there are encouraging examples of cohort analysis conducted in Taiwan and Hong Kong (Achen \& Wang, 2019; Huang, 2019). 
Third, it would be useful to set more emphases on identifying intra-generational differences besides inter-generational ones. With a rapidly polarizing and stratifying societies, it is increasingly possible that a cohort face same societal experiences which are interpreted rather differently depending on conditions like family background, school environment and neighborhood. Such generational fractions have common denominators but at the same time may hold opposing views and preferences as an outcome of these experiences. Tensions between generational fractions is an important tool to understand changes in political field as well perceptions concerning social inequalities.

\section{Further Reading}

Blais, A., \& Rubenson, D. (2013). The Source of Turnout Decline. Comparative Political Studies, 46(1), 95-117.

Dalton, R. J. (2017). The Participation Gap: Social Status and Political Inequality. Oxford: Oxford University Press.

Edmunds, J., \& Turner, B. (2002). Generational Consciousness, Narrative and Politics. Lanham: Rowman \& Littlefield Publishers.

Foa, R. S., \& Mounk, Y. (2016). The Danger of Deconsolidation: The Democratic Disconnect. Journal of Democracy, 27(3), 5-17.

Glenn, N. D. (2005). Cohort Analysis: Second Edition. Thousand Oaks: SAGE Publications.

Jennings, M. K., \& Niemi, R. G. (1981). Generations and Politics: A Panel Study of Young Adults and Their Parents. Princeton: Princeton University Press.

Mannheim, K. (1952). The Problem of Generations. In Essays on the Sociology of Knowledge (pp. 276-322). New York: Routledge.

Norris, P. (2011). Democratic Deficit: Critical Citizens Revisited. Cambridge: Cambridge University Press.

O'Brien, R. (2015). Age-Period-Cohort Models: Approaches and Analyses with Aggregate Data. Boca Raton: CRC Press.

Smets, K., \& van Ham, C. (2013). The embarrassment of riches? A meta-analysis of individuallevel research on voter turnout. Electoral Studies, 32(2), 344-359.

van der Brug, W., \& Kritzinger, S. (2012). Generational differences in electoral behaviour. Electoral Studies, 31(2), 245-249. 
Yang, Y., \& Land, K. C. (2013). Age-Period-Cohort Analysis: New Models, Methods, and Empirical Applications. Boca Raton, FL: CRC Pressl Taylor \& Francis.

\section{References}

Abramson, P. R. (1976). Generational Change and the Decline of Party Identification in America: 1952-1974. American Political Science Review, 70(2), 469-478.

Abramson, P. R. (1979). Developing Party Identification: A Further Examination of Life-Cycle, Generational, and Period Effects. American Journal of Political Science, 23(1), 78-96.

Achen, C. H., \& Wang, T. Y. (2019). Declining voter turnout in Taiwan : A generational effect? Electoral Studies, 58(January), 113-124.

Amnå, E., \& Ekman, J. (2014). Standby citizens: diverse faces of political passivity. European Political Science Review, 6(02), 261-281.

Bell, A., \& Jones, K. (2013). The impossibility of separating age, period and cohort effects. Social Science \& Medicine, 93, 163-165.

Bell, A., \& Jones, K. (2018). The hierarchical age - period - cohort model : Why does it find the results that it finds? Quality \& Quantity, 52(2), 783-799.

Bennett, W. L., \& Segerberg, A. (2013). The Logic of Connective Action: Digital Media and the Personalization of Contentious Politics. Information Communication and Society (Vol. 15). Cambridge: Cambridge University Press.

Bhatti, Y., \& Hansen, K. M. (2012a). Leaving the Nest and the Social Act of Voting: Turnout among First-Time Voters. Journal of Elections, Public Opinion and Parties, 22(4), 380406.

Bhatti, Y., \& Hansen, K. M. (2012b). The effect of generation and age on turnout to the European Parliament - How turnout will continue to decline in the future. Electoral Studies, 31(2), 262-272.

Bhatti, Y., Hansen, K. M., \& Wass, H. (2012). The relationship between age and turnout: A roller-coaster ride. Electoral Studies, 31(3), 588-593.

Bhatti, Y., Hansen, K. M., \& Wass, H. (2016). First-time boost beats experience: The effect of past eligibility on turnout. Electoral Studies, 41, 151-158.

Blais, A., Gidengil, E., Nevitte, N., \& Nadeau, R. (2004). Where does turnout decline come from? European Journal of Political Research, 43(2), 221-236.

Braungart, R. G., \& Braungart, M. M. (1986). Life-Course and Generational Politics. Annual Review of Sociology, 12, 205-231.

Crittenden, J. (1963). Aging and Political Participation. Political Research Quarterly, 16(2), 323331.

Crittenden, John. (1962). Aging and Party Affiliation. Public Opinion Quarterly, 26(4), 648-657. 
Cutler, N. E. (1969). Generation, Maturation, and Party Affiliation: A Cohort Analysis. Public Opinion Quarterly, 33(4), 583-588.

Dalton, R. J., McAllister, I., \& Wattenberg, M. P. (2000). The consequences of partisan dealignment. In R. J. Dalton \& M. P. Wattenberg (Eds.), Parties Without Partisans (pp. 3763). Oxford: Oxford University Press.

Dassonneville, R. (2017). Age and Voting. In K. Arzheimer, J. Evans, \& M. S. Lewis-Beck (Eds.), The SAGE Handbook of Electoral Behaviour (pp. 137-158). Los Angeles: Sage.

Delli Carpini, M. X. (1986). Stability and Change in American Politics The Coming of Age of the Generation of the 1960's. New York: New York University PRess.

Dinas, E., \& Stoker, L. (2014). Age-Period-Cohort analysis: A design-based approach. Electoral Studies, 33, 28-40.

European Commission. (2007). Young Europeans: Survey among Young People Aged between $15-30$ in the European Union (Eurobarometer \#202).

Fieldhouse, E., \& Cutts, D. (2012). The Companion Effect: Household and Local Context and the Turnout of Young People. Journal of Politics, 74(3), 856-869.

Fienberg, S. E., \& Mason, W. M. (1985). Specification and Implementation of Age, Period and Cohort Models. In Cohort Analysis in Social Research (pp. 45-88). New York: Springer.

Fosse, E., \& Winship, C. (2018). Moore-penrose estimators of age-period-cohort effects: Their interrelationship and properties. Sociological Science, 5, 304-334.

Franklin, M. N. (2004). Voter Turnout and the Dynamics of Electoral Competition since 1945. Cambridge: Cambridge University Press.

Gallego, A. (2009). Where Else Does Turnout Decline Come From? Education, Age, Generation and Period Effects in Three European Countries. Scandinavian Political Studies, 32(1), 2344.

Glenn, N. D., \& Grimes, M. (1968). Aging, Voting, and Political Interest. American Sociological Review, 33(4), 563-575.

Highton, B., \& Wolfinger, R. E. (2001). The First Seven Years of the Political Life Cycle. American Journal of Political Science, 45(1), 202-209.

Hooghe, M. (2004). Political Socialization and the Future of Politics. Acta Politica, 39(4), 331341.

Huang, C. (2019). Generation effects? Evolution of independence-unification views in Taiwan, 1996-2016. Electoral Studies, 58, 103-112.

Kertzer, D. I. (1983). Generation as a Sociological Problem. Annual Review of Sociology, 9(1), $125-149$.

Klecka, W. R. (1971). Applying Political Generations to the Study of Political Behavior: A Cohort Analysis. Public Opinion Quarterly, 35(3), 358-373.

Klingemann, H.-D., \& Fuchs, D. (Eds.). (1998). Citizens and the State. Oxford University Press. 
Konzelmann, L., Wagner, C., \& Rattinger, H. (2012). Turnout in Germany in the course of time: Life cycle and cohort effects on electoral turnout from 1953 to 2049. Electoral Studies, $31(2), 250-261$.

Linek, L., \& Petrúšek, I. (2016). What's past is prologue, or is it? Generational effects on voter turnout in post-communist countries, 1990-2013. Electoral Studies, 42, 78-90.

Luo, L. (2013). Assessing Validity and Application Scope of the Intrinsic Estimator Approach to the Age-Period-Cohort Problem. Demography, 50(6), 1945-1967.

Lyons, W., \& Alexander, R. (2000). A Tale of Two Electorates: Generational Replacement and the Decline of Voting in Presidential Elections. Journal of Politics, 62(4), 1014-1034.

Mason, K. O., Mason, W. M., Winsborough, H. H., \& Poole, W. K. (1973). Methodological Issues in Cohort Analysis of Archival Data. American Sociological Review, 38(2), 242-258.

Massing, P. (2002). Jugend und Politik: Jugenddebatten, Jugendforschung, Jugendpolitik. Schwalbach: Wochenschau-Verlag.

Milbrath, L. W. (1965). Political Participation: How and Why Do People Get Involved in Politics? Chicago: Rand McNally \& Company.

Neundorf, A., \& Niemi, R. G. (2014). Beyond political socialization: New approaches to age, period, cohort analysis. Electoral Studies, 33, 1-6.

Norris, P. (2002). Democratic Phoenix: Reinventing Political Activism. New York: Cambridge University Press.

Norris, P. (2003). Young people and political activism: From the politics of loyalties to the politics of choice? Report for the Council of Europe Symposium "Young people and democratic institutions: from disillusionment to participation" in Strasbourg.

Öhrvall, R. (2016). Voter turnout. In Oxford Handbook of Swedish Politics (pp. 229-245). Oxford: Oxford University Press.

Pelzer, B., te Grotenhuis, M., Eisinga, R., \& Schmidt-Catran, A. W. (2015). The Non-uniqueness Property of the Intrinsic Estimator in APC Models. Demography, 52(1), 315-327.

Persson, M., Wass, H., \& Oscarsson, H. (2013). The Generational Effect in Turnout in the Swedish General Elections, 1960-2010. Scandinavian Political Studies, 36(3), 249-269.

Quintelier, E. (2007). Differences in political participation between young and old people. Contemporary Politics, 13(2), 165-180.

Rao, C. R. (1973). Linear Statistical Inference and its Applications: Second Editon. New York: John Wiley \& Sons.

Russell, A., Fieldhouse, E., Purdam, K., \& Kalra, V. (2002). Voter engagement and young people. London: The Electoral Commission.

Sloam, J. (2016). Diversity and voice: The political participation of young people in the European Union. The British Journal of Politics and International Relations, 18(3), 521-537.

te Grotenhuis, M., Pelzer, B., Luo, L., \& Schmidt-Catran, A. W. (2016). The Intrinsic Estimator, 
Alternative Estimates, and Predictions of Mortality Trends: A Comment on Masters, Hummer, Powers, Beck, Lin, and Finch. Demography, 53(4), 1245-1252.

Torney-Purta, J. V. (2009). International psychological research that matters for policy and practice. American Psychologist, 64(8), 825-837.

Tozer, T. (2019, July 12). Brexit, democracy and intergenerational justice. Intergenerational Foundation.

van der Brug, W. (2010). Structural and Ideological Voting in Age Cohorts. West European Politics, 33(3), 586-607.

Verba, S., \& Nie, N. H. (1972). Participation in America: Social equality and political democracy. New York: Harper \& Row.

Verba, S., Schlozman, K. L., \& Brady, H. (1995). Voice and equality: Civic voluntarism in American politics. Harvard: Harvard University Press.

Wass, H. (2007). The effects of age, generation and period on turnout in Finland 1975-2003. Electoral Studies, 26(3), 648-659.

Wass, H. (2008). Generations and turnout. The generational effect in electoral participation in Finland (Acta Polit). Helsinki: Department of Political Science, University of Helsinki.

Wass, H., \& Blais, A. (2017). Turnout. In K. Arzhaimer, J. Evans, \& M. Lewis-Beck (Eds.), SAGE Handbook of electoral behaviour (pp. 459-487). London: Sage.

Winship, C., \& Harding, D. J. (2008). A Mechanism-Based Approach to the Identification of Age-Period-Cohort Models. Sociological Methods \& Research, 36(3), 362-401.

Wolfinger, R. E., \& Rosenstone, S. J. (1980). Who votes? New Heaven: Yale University Press.

Yang, Y., \& Land, K. C. (2006). A mixed models approach to the age-period-cohort analysis of repeated cross-section surveys, with an application to data on trends in verbal test scores. Sociological Methodology, 366(1), 75-97.

\section{Notes:}

${ }^{1}$ In fact, Figure 2 also demonstrates that the relationship between age and electoral participation gets a bit more complicated among the youngest voters. During the first years after enfranchisement, young adults usually leave their parental home and become less affected by their parents' higher propensity to vote (Bhatti \& Hansen, 2012a; Bhatti, Hansen, \& Wass, 2012; 
Fieldhouse \& Cutts, 2012). Therefore, the turnout tends to decline between the ages of 18 to 21 and only gradually begins to follow the trend of a curvilinear relationship. Such "roller-coaster" association between age and turnout could be discovered because of the availability of individuallevel register data which include sufficient number of observations for every age group, especially the youngest cohorts (see Bhatti, Hansen and Wass 2012).

${ }^{2}$ Given that the two first data sets cover the entire electorate, comparison between 1987 and 1999 can be considered as aggregate panel design. The figures for two recent elections are in turn based on repeated cross-sectional samples.

${ }^{3}$ One example of the context-driven age effect is the prolongation of adolescence: many "adultroles", like getting married and having children and finding a permanent job (see Highton \& Wolfinger, 2001), currently take place at later stages at an individual's life cycle compared to the situation a couple of decades ago. 